\title{
PESQUISA QUALITATIVA: REFLEXÕES SOBRE O TRABALHO DE CAMPO
}

\author{
ROSÁLIA DUARTE \\ Departamento de Educação da Pontifícia Universidade Católica do Rio de Janeiro \\ rosalia@edu.puc-rio.br
}

\section{RESUMO}

Este trabalho discute algumas das dificuldades mais freqüentemente enfrentadas por pesquisadores em trabalhos de campo, no que diz respeito ao uso de metodologias de base qualitativa. Procura-se apresentar, no decorrer do texto, problemas que envolvem, por exemplo, a delimitação do universo de pesquisa, a definição de critérios para a seleção dos sujeitos a serem entrevistados, elaboração de roteiros de entrevistas e sua realização, organização e análise de dados qualitativos, entre outros, visando contribuir com as discussões relativas à adoção desse tipo de metodologia no campo educacional.

PESQUISA QUALITATIVA - TRABALHO DE CAMPO - PESQUISA ETNOGRÁFICA METODOLOGIA DE PESQUISA

\begin{abstract}
QUALITATIVE RESEARCH: REFLECTIONS ON FIELD WORK. This work discusses some of the most frequent difficulties faced by researchers doing field work in their use of qualitative based methodologies. The text aims to present problems such as defining the research universe, defining criteria to select who will be interviewed, developing and carrying out scripts, organizing and analyzing qualitative data etc. as a contribution to the discussion of the use of this type of methodology in the field of education.
\end{abstract}




\section{INTRODUÇÃO}

Uma pesquisa é sempre, de alguma forma, um relato de longa viagem empreendida por um sujeito cujo olhar vasculha lugares muitas vezes já visitados. Nada de absolutamente original, portanto, mas um modo diferente de olhar e pensar determinada realidade a partir de uma experiência e de uma apropriação do conhecimento que são, aí sim, bastante pessoais.

Contudo, ao escrevermos nossos relatórios de pesquisa ou teses de doutorado, muitas vezes nos esquecemos de relatar o processo que permitiu a realização do produto. É como se o material no qual nos baseamos para elaborar nossos argumentos já estivesse lá, em algum ponto da viagem, separado e pronto para ser coletado e analisado; como se os "dados da realidade" se dessem a conhecer, objetivamente, bastando apenas dispor dos instrumentos adequados para recolhê-los.

Não parece ser assim que as coisas se passam. A definição do objeto de pesquisa assim como a opção metodológica constituem um processo tão importante para o pesquisador quanto o texto que ele elabora ao final. De acordo com Brandão (2000), a tão afirmada, mas nem sempre praticada, "construção do objeto" diz respeito, entre outras coisas, à capacidade de optar pela alternativa metodológica mais adequada à análise daquele objeto. Se nossas conclusões somente são possíveis em razão dos instrumentos que utilizamos e da interpretação dos resultados a que o uso dos instrumentos permite chegar, relatar procedimentos de pesquisa, mais do que cumprir uma formalidade, oferece a outros a possibilidade de refazer o caminho e, desse modo, avaliar com mais segurança as afirmações que fazemos.

\section{REFLEXÕES SOBRE O TRABALHO DE CAMPO}

De modo geral, durante a realização de uma pesquisa algumas questões são colocadas de forma bem imediata, enquanto outras vão aparecendo no decorrer do trabalho de campo. A necessidade de dar conta dessas questões para poder encerrar as etapas da pesquisa freqüentemente nos leva a um trabalho de reflexão em torno dos problemas enfrentados, erros cometidos, escolhas feitas e dificuldades descobertas.

Este trabalho surgiu da necessidade de partilhar algumas informações e reflexões acerca do recurso à pesquisa qualitativa que, apesar dos riscos e dificuldades que impõe, revela-se sempre um empreendimento profundamente instigante, agradável e desafiador. 


\section{A SELEÇÃO DE SUJEITOS EM ABORDAGENS QUALITATIVAS}

De um modo geral, pesquisas de cunho qualitativo exigem a realização de entrevistas, quase sempre longas e semi-estruturadas. Nesses casos, a definição de critérios segundo os quais serão selecionados os sujeitos que vão compor o universo de investigação é algo primordial, pois interfere diretamente na qualidade das informações a partir das quais será possível construir a análise e chegar à compreensão mais ampla do problema delineado. A descrição e delimitação da população base, ou seja, dos sujeitos a serem entrevistados, assim como o seu grau de representatividade no grupo social em estudo, constituem um problema a ser imediatamente enfrentado, já que se trata do solo sobre o qual grande parte do trabaIho de campo será assentado.

A pesquisa que gerou as reflexões trazidas neste trabalho (Duarte, 2000), tinha como objeto de estudo o processo de formação profissional de cineastas brasileiros e, nesse caso, a escolha dos entrevistados esteve vinculada à necessidade de compreender o referencial simbólico, os códigos e as práticas daquele universo cultural específico, que não apresenta contornos muito bem definidos. Como saber, por exemplo, quem de fato pertencia, naquele momento, à categoria de cineasta no Brasil? Se não se trata de uma profissão legalmente regulamentada, com exigências explícitas do ponto de vista da formação escolar/acadêmica, como saber quem poderia ser considerado diretor de cinema? A partir de que critérios passa-se a ser considerado membro de uma categoria profissional desse tipo? Essas questões precisaram ser respondidas antes do início do trabalho de campo.

Entre 1988 e 1990, uma equipe de pesquisadores da Universidade Paris 8 , na França, realizou uma investigação que tinha como objeto de estudo as formas de aprendizagem e de organização de uma categoria profissional denominada Les Réalisateurs', que, naquele contexto, é composta por diferentes setores cujas atividades estão relacionadas a produtos audiovisuais - cinema, televisão, vídeo, publicidade, filmes institucionais, filmes e vídeos educativos, documentários entre outras.

I. Essa pesquisa não foi publicada até o presente momento em razão de divergências surgidas entre os financiadores ao final de sua elaboração. $O$ acesso a cópias somente é permitido na Biblioteca do Centro Nacional de Cinematografia da França e foi lá que obtive, do diretor geral da biblioteca, o exemplar de que disponho. Em muitos momentos da pesquisa busquei referências nos resultados obtidos naquela investigação, com os quais procurei estabelecer algum nível de diálogo. 
A primeira parte do relatório dessa pesquisa fala, justamente da enorme dificuldade encontrada pela equipe de delimitar seu universo de estudo e buscar uma definição, mesmo que provisória, para um meio profissional resistente a qualquer categorização genérica. Os pesquisadores assinalam que desde o começo puderam perceber que, quando se trata de um setor ou grupo social cujas delimitações são muito fluidas, a definição da base da enquete constitui-se um problema.

Naquele caso, a solução encontrada foi a de trabalhar com três abordagens diferentes - uma genealógica: origem social do termo "realizador"; uma empírica: verificar, mediante a pesquisa qualitativa, como os realizadores se percebem e a partir de que categorias organizam o discurso sobre sua atividade profissional; e outra, bibliográfica: análise de textos profissionais, da imprensa especializada e de documentos sindicais.

Vencida essa etapa, a equipe considerou possível traçar um esboço da categoria profissional em questão, partindo para a elaboração de um cadastro com dados biográficos dos sujeitos reconhecidos pelo meio como profissionais da área. Esses dados foram obtidos por meio de cadastros de instituições ou entidades de classe e da realização de entrevistas semi-estruturadas com representantes dessas instituições. Com isso, organizou-se um banco de dados com referências de todos os realizadores de audiovisual em atividade na França naquele momento. Do banco de dados foram selecionados os sujeitos que viriam a ser entrevistados por meio de surveys.

A pesquisa sobre cineastas brasileiros também exigiu um mapeamento da população em estudo e a adoção de critérios bem definidos para a seleção dos entrevistados. Nesse caso, optou-se pelo sistema de rede ${ }^{2}$, no qual se busca um "ego" focal que disponha de informações a respeito do segmento social em estudo e que possa "mapear" o campo de investigação, "decodificar" suas regras, indicar pessoas com as quais se relaciona naquele meio e sugerir formas adequa-

2. De acordo com Bott (1976), o conceito de rede tem sido usado com tantos fins que se tornou difícil adotar universalmente qualquer conjunto de definições ou mesmo alcançar o sentido para o qual demonstra maior utilidade. Portanto, adverte o autor, é preciso esclarecer, em cada estudo empírico, de que maneira e em que perspectiva pretende-se adotá-lo. Nessa pesquisa, o conceito de rede tem como referência a concepção adotada por Bott: "a rede é definida como todas ou algumas unidades sociais (indivíduos ou grupos) com as quais um indivíduo particular ou um grupo está em contato" (p. 299). Trata-se, aqui, de uma "rede pessoal" na qual existe um ego focal que está em contato direto ou indireto (através de seus inter-relacionamentos) com qualquer outra pessoa situada dentro da rede (p. 300-302). 
das de abordagem. De um modo geral, as pessoas indicadas pelo "ego" sugerem que se procurem outras ou fazem referência a sujeitos importantes no setor e assim se vai, sucessivamente, amealhando novos "informantes". Essa é uma alternativa muito utilizada em pesquisas qualitativas e se tem mostrado produtiva. Alguém do meio, a partir do próprio ponto de vista, tem, relativamente, melhores condições de fornecer informações sobre esse meio do que alguém que observa, inicialmente de fora.

No meu caso, uma longa entrevista com um professor de cinema da Universidade Federal Fluminense ajudou a esboçar um mapa do grupo profissional em estudo e iniciar uma rede que viria permitir a incorporação progressiva de novos sujeitos à pesquisa. Vale dizer que esse professor veio a participar ainda de etapas posteriores da pesquisa, orientando eventualmente a seleção de entrevistados ou mesmo contribuindo para a análise da adequação de hipóteses ad hoc formuladas ao longo da investigação.

Contatos posteriores com o sindicato da categoria permitiriam a obtenção de informações mais precisas acerca de suas formas e instâncias de organização e de reconhecimento oficial. $\bigcirc$ sindicato dispunha, na ocasião, de um anuário relativamente atualizado, no qual constavam nomes e endereços de técnicos da indústria cinematográfica que exercem suas atividades nas regiões Norte, Nordeste, Sudeste e Centro-Oeste, incluídas, aí, algumas centenas de pessoas oficialmente registradas como diretores de cinema.

Um dicionário de cineastas brasileiros, que também é uma forma de legitimação (Miranda, 1990) tornou-se, igualmente, fonte de consulta, pois trazia dados biográficos e filmográficos, incluindo participações em festivais e premiações de diretores de cinema socialmente reconhecidos, dados esses que viriam a ajudar na preparação das entrevistas. Desse modo, associando informações advindas de diferentes fontes, foi possível organizar um pequeno banco de dados, relativamente detalhado, que passou a funcionar como base para a construção da população da pesquisa.

\section{DELIMITAÇÃO DO UNIVERSO DE SUJEITOS A SEREM ENTREVISTADOS}

Numa metodologia de base qualitativa o número de sujeitos que virão a compor o quadro das entrevistas dificilmente pode ser determinado a prioritudo depende da qualidade das informações obtidas em cada depoimento, assim como da profundidade e do grau de recorrência e divergência destas informa- 
ções. Enquanto estiverem aparecendo "dados" originais ou pistas que possam indicar novas perspectivas à investigação em curso as entrevistas precisam continuar sendo feitas.

À medida que se colhem os depoimentos, vão sendo levantadas e organizadas as informações relativas ao objeto da investigação e, dependendo do volume e da qualidade delas, o material de análise torna-se cada vez mais consistente e denso. Quando já é possível identificar padrões simbólicos, práticas, sistemas classificatórios, categorias de análise da realidade e visões de mundo do universo em questão, e as recorrências atingem o que se convencionou chamar de "ponto de saturação", dá-se por finalizado o trabalho de campo, sabendo que se pode (e deve) voltar para esclarecimentos.

No que diz respeito ao número de pessoas entrevistadas, o procedimento que se tem mostrado mais adequado é o de ir realizando entrevistas (a prática tem indicado um mínimo de 20, mas isso varia em razão do objeto e do universo de investigação), até que o material obtido permita uma análise mais ou menos densa das relações estabelecidas naquele meio e a compreensão de "significados, sistemas simbólicos e de classificação, códigos, práticas, valores, atitudes, idéias e sentimentos" (Dauster, 1999, p. 2). Eventualmente é necessário um retorno ao campo para esclarecer dúvidas, recolher documentos ou coletar novas informações sobre acontecimentos e circunstâncias relevantes que foram pouco explorados nas entrevistas.

Na pesquisa a que se refere este texto, o trabalho de campo foi interrompido quando se avaliou que com o material obtido seria possível: I) identificar padrões simbólicos e práticas empregadas no universo estudado; 2) descrever e analisar diferentes trajetórias profissionais e construir hipóteses relativas ao processo de formaçãa e de socialização profissional; 3) identificar valores, concepções, idéias, referenciais simbólicos que organizam as relações no interior desse meio profissional, buscando compreender seus códigos, o ethos ${ }^{3}$ profissional, mitos, rituais de consagração e legitimação, diferentes visões de cinema e concepções de aprendizagem do ofício e 4) configurar algum nível de generalização no que dizia respeito a essa categoria profissional, ao seu sistema de aprendizagem, regras de funcionamento, relação com o trabalho, rituais de ingresso e de consagração e assim por diante.

3. Entendido como aspectos morais, estéticos e valorativos de uma cultura determinada. 
Para Dauster (idem), esse tipo de trabalho de campo tem como objetivo "compreender as redes de significado a partir do ponto de vista do 'outro', operando com a lógica e não apenas com a sistematização de suas categorias" (p. 2) e não deve ser interrompido enquanto essa lógica não puder ser, minimamente, compreendida.

\section{SITUAÇÃO DE CONTATO}

As situações nas quais se verificam os contatos entre pesquisador e sujeitos da pesquisa configuram-se como parte integrante do material de análise. Registrar o modo como são estabelecidos esses contatos, a forma como o entrevistador é recebido pelo entrevistado, o grau de disponibilidade para a concessão do depoimento ${ }^{4}$, o local em que é concedido (casa, escritório, espaço público etc.), a postura adotada durante a coleta do depoimento, gestos, sinais corporais e/ou mudanças de tom de voz etc., tudo fornece elementos significativos para a leitura/interpretação posterior daquele depoimento, bem como para a compreensão do universo investigado.

Entrevistas realizadas em locais de trabalho, por exemplo, geralmente trazem problemas difíceis de solucionar: situações externas freqüentemente as interrompem (um telefonema "importante", uma decisão "urgente", a secretária, recados etc.), fazendo com que o entrevistado perca o "fio da meada" e se veja obrigado a retomar a narrativa de um outro ponto ou, até mesmo, a desistir de vez daquele assunto. Pessoas conversando e transitando por salas contíguas, telefones tocando, a agenda aberta sobre a mesa a lembrar outros compromissos, enfim, a presença marcante dos sinais que caracterizam ambientes designados como "de trabalho" costumam aguçar a ansiedade com relação ao tempo de duração do depoimento, interrompendo o livre fluxo de idéias e precipitando a interrupção do depoimento.

Em geral esse tipo de entrevista flui muito mais tranqüilamente quando realizada na residência da pessoa entrevistada. Em ambiente doméstico, privado, parece haver mais liberdade para expressão das idéias e menos preocupação com o tempo. Por essa razão, essas costumam ser entrevistas mais longas e, de modo

4. Vale lembrar que, em se tratando de entrevistas de uma hora e meia a duas horas de duração, deve-se esperar um certo nível de ansiedade por parte do entrevistado no que diz respeito ao tempo. 
geral, mais densas e produtivas. Vale a pena sugerir, quando da solicitação da entrevista, que o depoimento seja colhido na residência de quem vai concedê-lo.

Outras formas de contato podem também integrar estratégias de investigação qualitativa como conversas informais em eventos dos quais participam pessoas ligadas ao universo investigado (desde que registradas de algum modo - de preferência, no diário de campo) e coleta de informações adicionais, realizadas de forma mais ou menos regular, por telefone e/ou por correio eletrônico. Nesse caso, tratase de um material complementar à pesquisa e, embora não se constitua foco central da análise, participa significativamente desta.

\section{A REALIZAÇÃO DE ENTREVISTAS}

Aprender a realizar entrevistas é algo que depende fundamentalmente da experiência no campo. Por mais que se saiba, hipoteticamente, aquilo que se está buscando, adquirir uma postura adequada à realização de entrevistas semi-estruturadas, encontrar a melhor maneira de formular as perguntas, ser capaz de avaliar o grau de indução da resposta contido numa dada questão, ter algum controle das expressões corporais (evitando o máximo possível gestos de aprovação, rejeição, desconfiança, dúvida, entre outros), são competências que só se constroem na reflexão suscitada pelas leituras e pelo exercício de trabalhos dessa natureza.

Entrevista é trabalho, alerta Zaia Brandão (2000), e como tal "reclama uma atenção permanente do pesquisador aos seus objetivos, obrigando-o a colocar-se intensamente à escuta do que é dito, a refletir sobre a forma e conteúdo da fala do entrevistado" (p. 8) - além, é claro, dos tons, ritmos e expressões gestuais que acompanham ou mesmo substituem essa fala - e isso exige tempo e esforço.

À medida que perguntas vão sendo feitas diversas vezes, para diferentes pessoas, em circunstâncias diversas, e passamos a ouvir nossa própria voz nas gravações realizadas é que se torna possível avaliar criticamente nosso próprio desempenho e ir corrigindo-o gradativamente. Elaborar roteiros de entrevistas e formular perguntas podem, inicialmente, parecer tarefas simples, mas, quando disso depende a realização de uma pesquisa, não o é.

Em situações de coleta de depoimentos orais, posturas mais formais do tipo "respostas diretas a perguntas idem" não costumam produzir bons resultados e, quando acontecem, poucas vezes resistem às primeiras interrogações referentes a experiências de caráter pessoal. Falar de gostos e interesses pessoais, da relação com os pais, do ambiente familiar, da própria infância e juventude, dos amigos, de experiências escolares, de um modo geral, deixa as pessoas mais livres para expres- 
sarem idéias, valores, crenças, significações, expectativas de futuro, visões de mundo e assim por diante. Essas situações de contato exigem atenção redobrada por parte do pesquisador, pois ele corre o risco de ver a entrevista escapar-lhe completamente das mãos e perder-se dos objetivos da pesquisa, restringindo-se a divagações ou, mesmo, resvalando para uma espécie de "troca de experiências" mútuas, que compromete bastante a qualidade do trabalho.

Livros e artigos relatando vivências com entrevistas dessa modalidade e/ou coleta de depoimentos orais ou de histórias de vida são de grande valia, especialmente para pesquisadores iniciantes. Esses trabalhos costumam trazer orientações básicas sobre formas de solicitar entrevistas, posturas a serem adotadas ou evitadas nessas circunstâncias, erros mais comuns, elaboração de roteiros etc. Existem muitos manuais sobre o assunto e, por mais que possam parecer simplificados, são úteis na qualificação de pesquisadores ainda não experientes no uso dessa metodologia.

O recurso a entrevistas semi-estruturadas como material empírico privilegiado na pesquisa constitui uma opção teórico-metodológica que está no centro de vários debates entre pesquisadores das ciências sociais. Em geral, a maior parte das discussões trata de problemas ligados à postura adotada pelo pesquisador em situações de contato, ao seu grau de familiaridade com o referencial teórico-metodológico adotado e, sobretudo, à leitura, interpretação e análise do material recolhido (construído) no trabalho de campo.

Para Queiroz ( 1988), a entrevista semi-estruturada é uma técnica de coleta de dados que supõe uma conversação continuada entre informante e pesquisador e que deve ser dirigida por este de acordo com seus objetivos. Desse modo, da vida do informante só interessa aquilo que vem se inserir diretamente no domínio da pesquisa. A autora considera que, por essa razão, existe uma distinção nítida entre narrador e pesquisador, pois ambos se envolvem na situação de entrevista movidos por interesses diferentes.

Camargo (1984) concebe esse formato de entrevista menos como técnica de pesquisa do que como opção metodológica, pois implica uma teoria, e enfatiza as contribuições oferecidas nesse campo pela Antropologia e pela História. A seu ver, essas disciplinas, mais consensuais e homogêneas que as demais, oferecem uma experiência comum ao procedimento, bem como um legado teórico aceito, que devem ser tomados como referência na perspectiva de acumulação de saber científico nesse campo.

Durhan (1986) alerta para as muitas armadilhas embutidas no processo de identificação subjetiva que se estabelece nesse tipo de coleta da dados, especial- 
mente quando entrevistador e entrevistado compartilham um mesmo universo cultural. Nesses casos, adverte, corre-se sempre o risco de começar a explicar a realidade pelas categorias "nativas", ou seja, de passar a olhar a realidade exclusivamente pela ótica do interlocutor.

De acordo com Velho (1986), o risco existe sempre que um pesquisador lida com indivíduos próximos, às vezes conhecidos, com os quais compartilha preocupações, valores, gostos, concepções. No entanto, assinala que, quando se decide tomar sua própria sociedade como objeto de pesquisa, é preciso sempre ter em mente que sua subjetividade precisa ser "incorporada ao processo de conhecimento desencadeado" (p. 16), o que não significa abrir mão do compromisso com a obtenção de um conhecimento mais ou menos objetivo, mas buscar as formas mais adequadas de lidar com o objeto de pesquisa.

Esse autor sublinha que o uso de depoimentos colhidos nesse tipo de investigação implica a produção de um texto no qual os recortes das falas, os indivíduos privilegiados, os temas destacados e tantas outras formas de intervenção expressam menos as dúvidas e opiniões dos informantes que o posicionamento do pesquisador-autor. A preocupação teórica particular deste, referida à formação e aos interesses próprios, estabelece o distanciamento necessário para que seu discurso nunca se confunda com o de seus interlocutores ${ }^{5}$.

Analisando a forma como foram colhidos os depoimentos que compõem $\mathrm{La}$ Misère du Monde, livro de Pierre Bourdieu sobre pessoas "miseráveis", Nonna Mayer ( 1995 ) critica, exatamente, a ausência desse distanciamento. Segundo a autora, a maior parte das entrevistas realizadas pela equipe dirigida por Bourdieu contradiz, de forma sistemática, os princípios defendidos pelo próprio autor, em trabaIhos anteriores, quanto à natureza do papel do sociólogo como aquele que, dotado de um "habitus científico", é capaz de reinserir o discurso do interlocutor no contexto social e cultural do qual ele é produto.

Embora reconheça o papel inovador da equipe que desenvolveu esse trabaIho, bem como o valor da obra, a autora contesta a opção feita por Bourdieu de

5. Tais considerações levaram-me à decisão de nunca fazer referência, em artigos ou relatórios de pesquisa, aos nomes verdadeiros das pessoas que concedem os depoimentos. Entendo que ao recortar e editar as falas desses sujeitos, ao produzir diálogos fictícios entre pessoas que não se falaram, ao cruzar relatos orais e discursos acadêmicos, produzo um texto de minha autoria e de minha inteira responsabilidade, embora tenha como fonte as falas das pessoas entrevistadas. 
intensificar a proximidade social e cultural entre entrevistados e entrevistadores (que teriam sido incentivados, inclusive, a entrevistar amigos e parentes), reduzindo, portanto, o distanciamento. Essa postura, a seu ver, permitiu uma excessiva interferência no discurso do interlocutor, assim como inversões no papel do sociólogo que, ao se colocar atrás da voz do entrevistado, teria ficado reduzido a um écrivain public, a quem cabe apenas apresentar, sem traí-las, as mensagens que lhe são confiadas.

As formas de colher, transcrever e interpretar relatos orais têm sido objeto de severas críticas por parte da sociologia, no que diz respeito à chamada "garantia de confiabilidade". No entanto, alguns estudos vêm mostrando a viabilidade de se estabelecerem critérios rigorosos para avaliação de confiabilidade de conclusões que se baseiam nesse procedimento de investigação. Em 1997, a revista Sociology publicou estudo empírico no qual pesquisadores ingleses sugerem um procedimento a que denominam inter-rater reliability como um desses critérios.

O que eles propõem é, basicamente, que os relatos gravados e transcritos, assim como os procedimentos utilizados para colhê-los, sejam acessíveis a diferentes pesquisadores que não participam da pesquisa em questão, para que cada um possa fazer suas própria interpretação do conteúdo dos relatos colhidos e, dessa forma, auxiliar na validação dos resultados apresentados (Armstrong et al., 1997).

Nos limites impostos a trabalhos dessa natureza, procurar seguir o modelo ora proposto, entre outros, levando procedimentos, análises, hipóteses etc. ao conhecimento e crítica de outros pesquisadores, em momentos distintos da investigação, pode contribuir para a garantia de confiabilidade e legitimidade de resultados/ interpretações apresentados ao final da pesquisa. Anexar transcrições completas de parte das entrevistas ao corpo do relatório de pesquisa, para que o leitor possa ter acesso ao chamado "material bruto" e tirar suas conclusões, também pode funcionar como estratégia a ser empreendida nessa mesma direção.

\section{PROBLEMAS MAIS FREQÜENTES COM O ROTEIRO DA ENTREVISTA}

De maneira geral, a realização de entrevistas nos obriga a rever o roteiro. Uma das razões é, por exemplo, quando o entrevistador sente necessidade de explicar a pergunta ao entrevistado, ou seja, todas as vezes em que é formulada, tal pergunta suscita tantas dúvidas que é preciso reiterar sempre o que se quer, de fato, saber. Nesse caso, é melhor retirá-la do roteiro, pois, quando se tenta explicar demais, acaba-se dizendo, de um modo ou de outro, o que se espera que o outro responda. 
Algumas perguntas levam a divagações intermináveis e precisam ser repensadas, sob pena de acrescentarem ao material "bruto" uma enorme quantidade de informações "descartáveis", que dificultarão, em muito, o processo analítico.

Há, ainda, a dificuldade de se obterem respostas condizentes com os objetivos traçados para uma dada pergunta. Esse problema ocorreu no curso da investigação a que este trabalho faz referência, no tocante à questão relacionada aos filmes que teriam sido importantes na vida dos entrevistados. Formulada de maneira direta: "que filmes foram importantes na sua vida?", a pergunta suscitava respostas carregadas de critérios formais de julgamento de obras cinematográficas: eram importantes os filmes designados como tal pelos cânones da crítica de cinema e/ou da cinefilia. Desse modo, a lista de filmes "marcantes" era praticamente a mesma em todas as entrevistas. Não que a resposta fosse artificial; era profundamente verdadeiro que certos filmes tivessem sido, de fato, "definitivos" para a maioria daquelas pessoas.

No entanto, eram outros os objetivos que levaram à formulação daquela pergunta - esperava-se não só identificar o sistema de referência-padrão daquele grupo social, mas, principalmente, obter um material pessoal, mais subjetivo, que permitisse levantar hipóteses acerca de como são estabelecidas as relações "amorosas" (afetivas) entre os espectadores e seus filmes preferidos, fora dos parâmetros da racionalidade crítica de quem domina o assunto. Tencionava-se buscar um inventário de emoções mobilizadas por imagens fílmicas, descrevendo marcas que esse tipo de imagem deixa na memória.

A discussão com outros pesquisadores possibilitou a identificação da natureza do problema: era preciso tentar trazer à tona reminiscências de filmes sobre os quais não se tinha grandes expectativas antes de vê-los, filmes que não tinham sido objeto de crítica, de premiações ou coisas do tipo. Desejava-se resgatar lembranças de cenas ou seqüências vistas (vividas) na sala escura, em um momento da vida em que não havia, ainda, o crivo do conhecimento "intelectual" do cinema, estética e/ ou politicamente condicionado. E isso não seria conseguido com uma indagação direta. Nesse ponto, a formulação de uma outra pergunta, além da que já vinha sendo feita, possibilitou alcançar a meta traçada.

Muitos problemas podem ser identificados no roteiro das entrevistas quando elas saem do papel (ou do computador) e ganham significado na interação entrevistador/entrevistado. Por essa razão, este deve ser um instrumento flexível para orientar a condução da entrevista e precisa ser periodicamente revisto para que se possa avaliar se ainda atende os objetivos definidos para aquela investigação. 


\section{ANÁLISE DE “DADOS” QUALITATIVOS}

Métodos qualitativos fornecem dados muito significativos e densos, mas, também, muito difíceis de se analisarem. Sempre se lê isso em textos sobre metodologias de pesquisa em ciências sociais, entretanto só se tem idéia da dimensão dessa afirmação quando se está diante de seu próprio material de pesquisa e se sabe que é preciso dar conta dele.

De modo geral, ao final de um trabalho de campo relativamente extenso, pode-se ter em mãos em torno de trinta entrevistas semi-estruturadas, de uma hora e meia cada (cuja transcrição dá, em média, vinte a vinte e cinco laudas); registros escritos de conversas não gravadas; eventuais mensagens trocadas por correio eletrônico; notas de campo; materiais audiovisuais; textos e/ou reportagens sobre o tema, publicados em jornais e revistas; notas biográficas e, ainda, dados de outras pesquisas sobre o mesmo tema ou temas afins.

Esse material precisa ser organizado e categorizado segundo critérios relativamente flexíveis e previamente definidos, de acordo com os objetivos da pesquisa. É um trabalho árduo e, numa primeira etapa, mais "braçal" do que propriamente analítico.

Para ajudar na realização de tarefas que envolvem essa etapa da análise de dados coletados/construídos em pesquisas qualitativas, dispõe-se de bons aplicativos para microcomputadores pessoais que facilitam bastante o trabalho. Esses aplicativos criam um ambiente digital no qual se podem gerenciar e explorar diferentes documentos (entrevistas, notas de campo, relatórios, tabelas e gráficos importados de programas de análise de dados quantitativos etc.), criar categorias, codificar textos, fazer cruzamentos, uniões, interseções de códigos já criados, armazenar idéias, lembretes e notas sobre os dados, importar e exportar dados de e para outros programas (editores de texto ou bancos de dados), além de estabelecer padrões de análise para a construção de hipóteses, entre outros recursos.

Esses programas podem ser utilizados na leitura/interpretação de materiais advindos de pesquisa do tipo etnográfica (incluindo diários de campo), de estudos de caso, de trabalhos com grupos focais, entre outras metodologias qualitativas, e possibilitam, inclusive, a construção de teorias a partir da combinação, confrontação e teste de materiais codificados. Entre os mais amigáveis, encontram-se o Folio Views e o NUD*IST.

Registrado como Qualitative Solutions and Research, para Windows e Macintosh, NUD*IST foi criado por um casal de pesquisadores (ele, analista de sistemas, ela, pesquisadora qualitativa) e desenvolvido em Melbourne, Austrália. 
Trata-se de um pacote destinado a auxiliar o usuário na análise de dados não numéricos e não estruturados, pela disponibilização de recursos para sua codificação por meio de um sistema de indexação de códigos e/ou pesquisas de texto (encontrar palavras, frases e expressões).

Vencida a etapa de organização/classificação do material coletado, cabe proceder a um mergulho analítico profundo em textos densos e complexos, de modo a produzir interpretações e explicações que procurem dar conta, em alguma medida, do problema e das questões que motivaram a investigação. As muitas leituras do material de que se dispõe, cruzando informações aparentemente desconexas, interpretando respostas, notas e textos integrais que são codificados em "caixas simbólicas", categorias teóricas ou "nativas" ajudam a classificar, com um certo grau de objetividade, o que se depreende da leitura/interpretação daqueles diferentes textos.

Assim, fragmentos de discursos, imagens, trechos de entrevistas, expressões recorrentes e significativas, registros de práticas e de indicadores de sistemas classificatórios constituem traços, elementos em torno dos quais construir-se-ão hipóteses e reflexões, serão levantadas dúvidas ou reafirmadas convicções. Aqui, como em todas as etapas de pesquisa, é preciso ter olhar e sensibilidade armados pela teoria, operando com conceitos e constructos do referencial teórico como se fossem um fio de Ariadne, que orienta a entrada no labirinto e a saída dele, constituído pelos documentos gerados no trabalho de campo.

Daqui para frente trata-se de produzir "resultados" e explicações cujo grau de abrangência e generalização depende do tipo de ponte que se possa construir entre o microuniverso investigado e universos sociais mais amplos.

\section{CONSIDERAÇÕES FINAIS}

Neste artigo procurou-se fazer uma apresentação sistemática de formas correntes de uso de certos procedimentos de pesquisa, sinalizando para as dificuldades e armadilhas mais comuns nessas circunstâncias.

Vale reafirmar que a confiabilidade e legitimidade de uma pesquisa empírica realizada nesse modelo dependem, fundamentalmente, da capacidade de o pesquisador articular teoria e empiria em torno de um objeto, questão ou problema de pesquisa. Isso demanda esforço, leitura e experiência e implica incorporar referências teórico-metodológicas de tal maneira que se tornem lentes a dirigir o olhar, ferramentas invisíveis a captar sinais, recolher indícios, descrever práticas, atribuir sentido a gestos e palavras, entrelaçando fontes teóricas e materiais empíricos como 
quem tece uma teia de diferentes matizes. Tal é, a meu ver, a aventura da pesquisa científica.

\section{REFERÊNCIAS BIBLIOGRÁFICAS}

ARMSTRONG, D. et al. The place of inter-rater reliability in qualitative research: an empirical study. Sociology, v.3 I, n.3, p. 597-606, ago. 1997.

BECKER, H. Métodos de pesquisa em Ciências Sociais. São Paulo: Hucitec, 1997.

BOTT, E. Familia e rede social. Rio de Janeiro: Francisco Alves, 1976.

BRANDÃO, Z. Entre questionários e entrevistas. In: NOGUEIRA, M. A.; ROMANELLI, G.; ZAGO, N. (orgs.). Familia \& escola. Rio de Janeiro: Vozes, 2000. p. I7I-83.

CAMARGO, A. Os Usos da história oral e da história de vida: trabalhando com elites políticas. Revista de Ciências Sociais, v. 27, n. I, p. 5-28, 1984.

CARDOSO, R. Aventuras de antropólogos em campo ou como escapar das armadilhas do método. In: CARDOSO, R. (org.). A Aventura antropológica: teoria e pesquisa. Rio de Janeiro: Paz e Terra, 1986. p. 95-106.

CIPRIANI, R. Biografia e cultura: da religião à política. In: VON SIMSON, O. M. (org. e intr.). In: Experimentos com histórias de vida (Itália-Brasil). São Paulo: Vértice, Editora Revista dos Tribunais, Enciclopédia Aberta de Ciências Sociais; v. 5, 1988. p. 106-42.

DAUSTER, T. A Fabricação de livros infanto-juvenis e os usos escolares: o olhar de editores. Revista Educação/PUC-Rio, n. 49, p. I - 18, nov. 1999.

DUARTE, R. Filmes, amigos e bares: a socialização de cineastas na cidade do Rio de Janeiro. Rio de Janeiro, 2000. Tese (dout.) Departamento de Educação, PUC.

DURHAN, E. R. A pesquisa antropológica com populações urbanas: problemas e perspectivas. In: CARDOSO, R. (org.). A Aventura antropológica: teoria e pesquisa. Rio de Janeiro: Paz e Terra, 1986, p. 17-38.

GEERTZ, C. A Interpretação das culturas. Rio de Janeiro: Guanabara Koogan, 1989.

MAGNANI, J. G. C. Discurso e representação, ou de como os Baloma de Kiriwina podem reencarnar-se nas atuais pesquisas. In: CARDOSO, R. (org.). A Aventura antropológica: teoria e pesquisa. Rio de Janeiro: Paz e Terra, 1986, p. 127-40.

LESRÉALISATEURS. Responsable: THONON, Marie. Chercheurs: BEC, Colette; BENARD, Monique; DELATTE, Jeanine; VILLEGLE, Valérie. Convention d'étude entre le CNC et l'AIC, Université Paris VIII, avec la participation de la SCAM et du Ministère de la Culture. Bibliotéque du CNC, Paris: brochura, 1990. 
MAYER, N. L'Entretien selon Pierre Bourdieu: analyse critique de La Misère du Monde. Revue Française de Sociologie, XXXVI, p. 355-70, 1995.

MIRANDA, L. F. Dicionário de cineastas brasileiros. São Paulo: Art Editora, Secretaria de Estado da Cultura, 1990.

QUEIROZ, M. I. P. Relatos orais: do "indizível” ao "dizível". In: VON SIMSON, O. M. (org. e intr.). Experimentos com histórias de vida (Itália-Brasil). São Paulo: Vértice, Editora Revista dos Tribunais, Enciclopédia Aberta de Ciências Sociais, v.5, 1988. p. 68-80.

VELHO, G. Subjetividade e sociedade: uma experiência de geração. Rio de Janeiro: Zahar, 1986. 